\title{
Exhibit of two German periscopes
}

This content has been downloaded from IOPscience. Please scroll down to see the full text. 1918 Trans. Opt. Soc. 2018

(http://iopscience.iop.org/1475-4878/20/1/304)

View the table of contents for this issue, or go to the journal homepage for more

Download details:

IP Address: 137.149.200.5

This content was downloaded on 02/10/2015 at 02:17

Please note that terms and conditions apply. 


\title{
EXHIBIT OF TWO GERMAN PERISCOPES
}

\author{
By Lr.-Col. A. C. WILLIAMS, R.A. \\ Exhibited toth October, $19 \times 8$
}

(1) A 5 foot periscope, made by Hensoldt Wetzler, No. 91 10. (Fig. I.)

The periscope has a magnification of $2 \cdot 2$ diameters and a field of view of I4 degrees. The definition is reasonably good although there is a certain amount of colour towards the edge of the field.

The overall length of the periscope is $4 \mathrm{ft} .9$ ins. The distance between the optical centres of the upper and lower prisms is $4 \mathrm{ft}$. I in.

There is nothing very novel in the design of the periscope, which is of the double telescope type, the light passing in parallel bundles between the two collecting lenses. The main tube is of steel; an aluminium adapter is screwed into the upper end to hold one collecting lens whilst the conical head is screwed to the projecting portion of the adapter. The upper prism is small and gives a small target to aim at: considerable care has been taken in the design of its mounting, to prevent its shifting and to ensure watertightness. The prism is silvered and is pressed against a rubber ring on its exposed surface.

The lower end of the main tube fits over an aluminium adapter carrying the second collecting lens and is secured to it by three screws. The lower prism is mounted so that it can be oriented to secure uprightness of image; a circular $\mathrm{U}$-groove in its mount is secured by grub screws. The prism is held at its two sides by spring clips which are capable of adjustment to secure the centrality of the beam entering the eyepiece. The latter is a focussing eyepiece of binocular type.

A hollow steel tube is fitted in the lower end of the periscope for fitting over a post, etc.

A light metal case is provided for holding the periscope.

(2) A smaller periscope, made by R. Fuess, No. 698. (Fig. 2.)

The eyepiece is missing, but the holder for it shews that it was inclined to the axis of the telescope at about $60^{\circ}$; the object of this no doubt being to allow a man wearing a steel helmet to use it. 

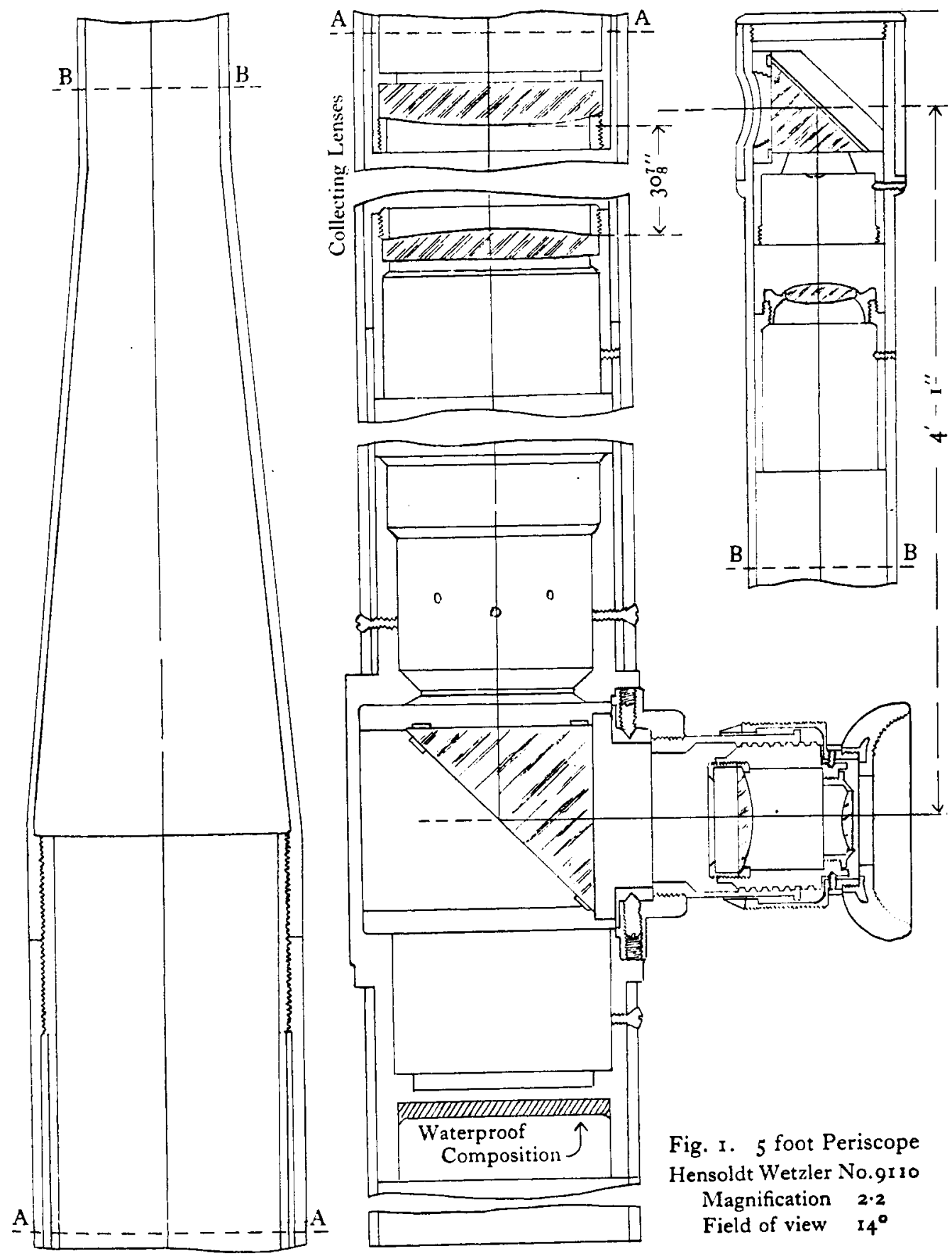

Fig. I. 5 foot Periscope Hensoldt Wetzler No.g110 Magnification $\mathbf{2 \cdot 2}$

Field of view $14^{\circ}$ 


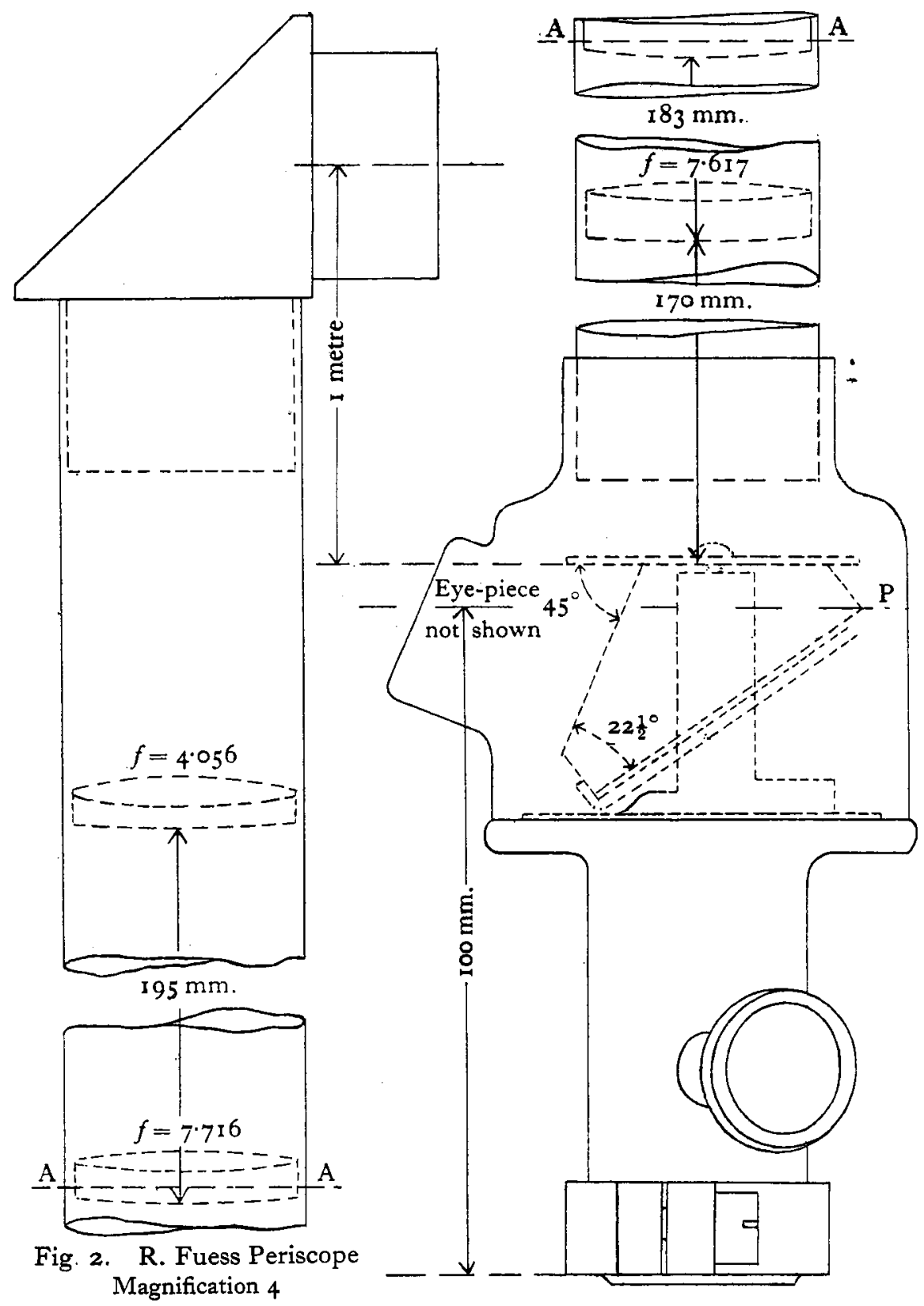

